\title{
Circulating matrix metalloproteinases and their tissue inhibitors as markers for ethnic variation in pelvic floor tissue integrity
}

\author{
DIAA E.E. RIZK ${ }^{1}$, GHADA AL-KAFAJI ${ }^{2}$, AHMED A. JARADAT ${ }^{3}$, DIAB AL-TAYAB ${ }^{2}$, \\ MOIZ BAKHIET $^{2}$ and STEFANO SALVATORE ${ }^{4}$ \\ ${ }^{1}$ Department of Obstetrics and Gynaecology, College of Medicine and Medical Sciences, Arabian Gulf University, Manama; \\ ${ }^{2}$ Department of Molecular Medicine, College of Medicine and Medical Sciences and \\ Al-Jawhara Centre for Molecular Medicine, Genetics and Inherited Disorders, Arabian Gulf University, Manama; \\ ${ }^{3}$ Department of Family and Community Medicine, College of Medicine and Medical Sciences, \\ Arabian Gulf University, 26671 Manama, Kingdom of Bahrain; ${ }^{4}$ Obstetrics and Gynaecology Unit, \\ Vita-Salute San Raffaele University, IRCCS San Raffaele Hospital, I-20132 Milan, Italy
}

Received March 23, 2018; Accepted June 15, 2018

DOI: $10.3892 /$ br.2018.1129

\begin{abstract}
The purpose of the present study was to measure the plasma levels of matrix metalloproteinases (MMP)-2 and -9 and their tissue inhibitors (TIMP)-1 and -2 , as surrogate biomarkers for pelvic floor tissue integrity in young, healthy multi-ethnic women. This was hoped to elucidate ethnic vulnerability to support-related pelvic floor dysfunctions. The plasma levels of MMP-2 and -9 and TIMP-1 and -2 were measured by sandwich ELISA in nulliparous, young (18-29 years) women volunteers $(n=85)$ from five ethnic groups [n=17/group; Bahrainis, other Arabs, Filipinos, Indians/Pakistanis and Caucasians (Italians)] and compared with levels in Italians as the reference group. It was identified that the levels of plasma MMP-2 were significantly higher in Italians than in Bahrainis $(\mathrm{P}<0.001)$ and Filipinos $(\mathrm{P}<0.001)$, but significantly lower than in Indians/Pakistanis $(\mathrm{P}=0.013)$; whereas, the levels of plasma MMP-9 were significantly higher in Italians than in Bahrainis $(\mathrm{P}=0.009)$ and Indians/Pakistanis $(\mathrm{P}<0.015)$. The levels of plasma TIMP-2 were significantly lower in Italians than in Indians/Pakistanis ( $\mathrm{P}=0.003)$, but the levels of plasma TIMP-1 were significantly higher in Italians than in all other groups $(\mathrm{P}<0.05)$ excluding Bahrainis. Although MMP-2 correlated negatively with TIMP-2 and MMP-9 correlated positively with TIMP-1, both correlations were not significant $(\mathrm{r}=0.071$, $\mathrm{P}=0.533$ and $\mathrm{r}=0.197, \mathrm{P}=0.8$, respectively). In all ethnic groups, MMP-9 level correlated positively with $\mathrm{BMI}(\mathrm{r}=0.26, \mathrm{P}=0.02)$,
\end{abstract}

Correspondence to: Dr Ghada Al-Kafaji, Department of Molecular Medicine, College of Medicine and Medical Sciences and Al-Jawhara Centre for Molecular Medicine, Genetics and Inherited Disorders, Arabian Gulf University, 293 Salmaniya Avenue, Road 2904, Block 329, 26671 Manama, Kingdom of Bahrain

E-mail: ghadaa@agu.edu.bh

Key words: collagen, connective tissue, ethnic, matrix metalloproteinases, matrix metalloproteinases inhibitors, pelvic floor and TIMP-2 level with age $(\mathrm{r}=0.23, \mathrm{P}=0.045)$. Overall, the trends for higher levels of MMP-2 and -9 and lower levels of TIMP-2 in the plasma of Caucasian women may indicate a greater tendency for collagenolysis and weaker connective tissue with increased risk of developing pelvic floor dysfunctions, and thus may potentially serve as biomarkers for pelvic floor tissue integrity.

\section{Introduction}

Support-related pelvic floor dysfunctions including pelvic organ prolapse (POP), stress urinary incontinence (SUI) and faecal incontinence are caused by structural defects in the complex supportive apparatus formed by the connective tissue and striated muscles of the pelvic floor (1-7). The role of the connective tissue component is to counteract both stretch and compression of the pelvic floor exerted by the gravitational and inertial forces of the intra-abdominal pressure and to repair damaged tissues $(2,4,6)$. This supportive function is determined by the tensile strength of collagen in the extracellular matrix that is maintained by continuous remodelling of collagen $(1,3)$. The latter depends on a critical balance between collagen degradation and production that is controlled by a group of enzymes, matrix metalloproteinases (MMPs) and their respective tissue inhibitors (TIMPs) $(1,3,5)$. The prevalence of support-related pelvic floor dysfunctions is affected by racial and ethnic origin, with a higher risk observed in Caucasians than in other populations (8-10). This may be explained by genetic, environmental and/or anatomical differences (8-10). Ethnic variation in the integrity of the pelvic floor connective tissue may be the possible genetic mechanism (10). This factor has been traditionally assessed by measuring the tissue levels of MMPs, particularly types 2 and 9, and their TIMPs, particularly types 1 and 2 , in the fascial components of the pelvic floor (1-6). However, to the best of our knowledge, circulating MMP and TIMP levels as surrogate biomarkers of pelvic floor tissue have not been previously measured in women with POP or correlated with tissue levels. 
Computational modelling with finite element analysis has recently improved understanding of the failure mechanisms of pelvic organ support under different loading conditions of the pelvis (11). Mechanical testing of pelvic floor supportive function is typically based on healthy young women before they develop pelvic floor dysfunction with irreversible stretching and deformation of supportive structures $(5,11)$. Studying the biomechanical relationship of pelvic floor support defects should thus be more reliable when examining the normal pelvic floor of asymptomatic women (10). The present study was conducted to test the hypothesis that there are ethnic differences in the circulating levels of MMP-2 and -9 and of TIMP-1 and -2 in asymptomatic Caucasian and non-Caucasian women, which may indicate variation in pelvic floor connective tissue remodelling. This variation may influence the potential risk of developing pelvic floor dysfunction.

\section{Materials and methods}

Study design and subject groups. The current study was a twocentre, cross-sectional study of 85 healthy female volunteers at the University Medical Centre of the College of Medicine and Medical Sciences Arabian Gulf University, Bahrain and the San Raffaele Hospital, Milan, Italy. The Bahrain centre provides tertiary ambulatory gynaecological care for a multi-ethnic population (primarily comprised of Arabs, Indians, Pakistanis and Filipinos). The Italian centre provides tertiary gynaecologic services to the Milan metropolitan area. The study protocol was approved by the Research Ethics Committees of both institutions.

In Bahrain, non-Caucasian subjects were recruited between February, 2016 and October, 2016 through advertisement within the University Centre's patient community. Each of the 5 study groups consisted of 17 nulliparous women aged 18-29 years selected from each of the three most prominent ethnic groups (Arabs, Filipinos, Indians/Pakistanis) living in Bahrain as well as Bahraini women. An Italian cohort $(n=17)$ served as proxy for Caucasians and was recruited in October and November, 2016 from San Rafael Hospital at patient meeting forums. Ethnicity was assigned by country of birth.

The sample size was calculated as the minimum number of subjects in each group with sufficient statistical power (two-sided significance at 0.05 with a power of $80 \%$ ) to detect a 20\% difference between the mean circulating MMP levels of groups [for instance $23.2 \mathrm{ng} / \mathrm{ml}$ plasma MMP-2 assuming that the mean \pm standard deviation $(\mathrm{SD})=116 \pm 26 \mathrm{ng} / \mathrm{ml}$ based on the results of a previous study (12).

The inherent effect of age and lifestyle variables including diurnal variation and exercise on the MMP assay performance were considered by including only younger women ( $\leq 29$ years of age) and obtaining blood samples in the morning prior to excessive physical activity. Older ( $>29$ years of age) and parous women were excluded to avoid the confounding effect of age and vaginal delivery, respectively, on pelvic floor integrity $(5,7,10)$. Subjects who agreed to participate gave written informed consent and were screened for the presence of support-related pelvic floor issues using the validated short form of the Pelvic Floor Distress Inventory (PFDI-20) (13). Women who scored $>0$ on PFDI-20 were excluded. Women with a history of renal, gastro-intestinal and/or neurological diseases, diabetes mellitus, hypertension and surgical operations on the pelvis, and those who were currently taking diuretics or anti-cholinergic medications were also excluded. Socio-demographic and lifestyle variables as well as information about medical disorders suggestive of weakness of connective tissue support (joint hyper-mobility, varicose veins, piles and previous hernia repair) were obtained. Inquiry about chronic constipation (fewer than three bowel movements per week for at least three months) was also added since this may be a risk factor for pelvic floor weakness (10). Enrolled women were not evaluated by pelvic examination as the majority of the Bahraini and Arab subjects were celibate. The Indian/Pakistani group were reimbursed 10 Bahraini dinars ( 1 dinar $\approx 2.25$ euros) for their time commitment to participate as healthy volunteers. Participants were interviewed and completed the self-reported PFDI-20 questionnaire during the hospital visit before obtaining the blood samples.

Blood sampling. Peripheral blood samples to assess the circulating levels of plasma MMP and TIMP were collected by phlebotomy between 8-11 a.m. from participants into EDTA tubes, mixed and placed on ice. The plasma was separated from the blood cells by centrifugation at $4^{\circ} \mathrm{C}$ at $2,000 \mathrm{x}$ g for $30 \mathrm{~min}$ and the samples were kept frozen at $-80^{\circ} \mathrm{C}$. Italian samples were similarly processed and transported frozen in liquid nitrogen at $-80^{\circ} \mathrm{C}$ to the central laboratory facility in Bahrain.

Sandwich ELISA. Total plasma MMP-2, MMP-9, TIMP-1 and TIMP-2 concentrations were measured by sandwich ELISA using commercially available human ELISA kits (catalogue nos. KHC3081, KHC3061, KHC1491 and KHC3081, respectively; Thermo Fisher Scientific, Inc., Waltham, MA, USA). In each assay, the proactive and active forms of both MMP-2 and -9 were processed according to the manufacturer's instructions, as previously described $(14,15)$. Prior to analysis, the samples were thawed briefly in a $37^{\circ} \mathrm{C}$ water bath and placed on ice. Plasma samples were then diluted with kit buffer (1:10) to allow measurement against a standard curve for MMP-9, TIMP-1 and TIMP-2 as per the kit instructions, and the results were averaged as the mean $\pm \mathrm{SD}$. Measurements were carried out in duplicate.

Plasma TIMP-1 and -2 levels were measured using the same technique but TIMP-1 and TIMP-2 were detected only in the active forms. Efforts were made to limit the effects of environmental conditions and storage processes on inter-assay variation and to standardize the conditions of laboratory measurement including quality control of pre-test samples (16). The analytic sensitivity of human MMP-2 and human MMP-9 was $<0.15 \mathrm{ng} / \mathrm{ml}$ and $<10 \mathrm{pg} / \mathrm{ml}$, respectively, and the intraand inter-assay coefficients of variation were 5.6 and 3.3\% for MMP-2 and 4.02 and $7.54 \%$ for MMP-9, respectively. The analytic sensitivity of human TIMP-1 and human TIMP-2 was $<1 \mathrm{ng} / \mathrm{ml}$ and $<2 \mathrm{pg} / \mathrm{ml}$, respectively, and the intra- and interassay coefficients of variation were 5.6 and $4 \%$ for TIMP-1 and $<10$ and $<12 \%$ for TIMP-2, respectively.

Statistical analysis. Data were analysed using SPSS 25.0 software (IBM Corporation, Armonk, NY, USA). Qualitative and quantitative data regarding patients' sociodemographic and clinical characteristics were expressed as number 
Table I. Socio-demographic characteristics of participants $(n=85)$.

\begin{tabular}{|c|c|c|c|c|c|}
\hline Characteristic & $\begin{array}{c}\text { Bahraini } \\
(\mathrm{n}=17) \mathrm{n}, \%\end{array}$ & $\begin{array}{c}\text { Arab } \\
(n=17) n, \%\end{array}$ & $\begin{array}{c}\text { Filipino } \\
(\mathrm{n}=17) \mathrm{n}, \%\end{array}$ & $\begin{array}{l}\text { Indian/Pakistani } \\
\quad(n=17) n, \%\end{array}$ & $\begin{array}{c}\text { Italian } \\
(\mathrm{n}=17) \mathrm{n}, \%\end{array}$ \\
\hline \multicolumn{6}{|c|}{ Educational level } \\
\hline Primary & 0 & 0 & 0 & $3(17.6)$ & 0 \\
\hline Secondary & 0 & 0 & 0 & $4(23.5)$ & 0 \\
\hline University & $17(100.0)$ & $17(100.0)$ & $17(100.0)$ & $10(58.8)$ & $17(100.0)$ \\
\hline \multicolumn{6}{|l|}{ Marital status } \\
\hline Single & $17(100.0)$ & $15(88.2)$ & $15(88.2)$ & $1(5.9)$ & $17(100.0)$ \\
\hline Married & 0 & $1(5.9)$ & $2(11.8)$ & $16(94.1)$ & 0 \\
\hline Divorced & 0 & $1(5.9)$ & 0 & 0 & 0 \\
\hline \multicolumn{6}{|c|}{ Income (Bahraini dinara/month) } \\
\hline$<1,000$ & $16(94.1)$ & $15(88.2)$ & $17(100.0)$ & $16(94.1)$ & $17(100.0)$ \\
\hline $1,000-1,500$ & $1(5.9)$ & $1(5.9)$ & 0 & 0 & 0 \\
\hline$>2,000$ & 0 & $1(5.9)$ & 0 & $1(5.9)$ & 0 \\
\hline \multicolumn{6}{|l|}{ Occupation } \\
\hline Student & $17(100.0)$ & $15(88.2)$ & $2(11.8)$ & 0 & $14(82.4)$ \\
\hline Housewife & 0 & 0 & 0 & $12(70.6)$ & $2(11.8)$ \\
\hline Professional & 0 & $2(11.8)$ & $15(88.2)$ & $4(23.5)$ & $1(5.9)$ \\
\hline Unemployed & 0 & 0 & 0 & $1(5.9)$ & 0 \\
\hline \multicolumn{6}{|l|}{ Smoking status } \\
\hline Non-smoker & $16(94.1)$ & $15(88.2)$ & $17(100.0)$ & $17(100.0)$ & $11(64.7)$ \\
\hline Smoker & $1(5.9)$ & $2(11.8)$ & 0 & 0 & $6(35.3)$ \\
\hline
\end{tabular}

${ }^{\mathrm{a}} 1$ Bahraini dinar $\approx 2.25$ euros.

(percentage) and the mean \pm standard deviation (SD), respectively, while the quantitative results of plasma MPP and TIPP measurements were expressed as the mean \pm SD and plotted graphically as box plots indicating the median, interquartile range and range. Outliers and extreme values were indicated as follows: An observation $\mathrm{x}$ was designated an outlier if $\mathrm{x}<\mathrm{Q} 1-1.5(\mathrm{IQR})$ or $\mathrm{x}>\mathrm{Q} 3+1.5(\mathrm{IQR})$; an observation $x$ was designated an extreme value if: $x<Q 1-3(I Q R)$ or $\mathrm{x}>\mathrm{Q} 3+3(\mathrm{IQR})$, where $\mathrm{Q} 1=$ first quartile, $\mathrm{Q} 3=$ third quartile and $\mathrm{IQR}=$ inter quartile range.

All differences were compared using Italians/Caucasians as the reference group by the Mann-Whitney U test, since the sample sizes were relatively small. Correlation between plasma MMP-2 and -9 and TIMP-1 and -2 levels was assessed using Pearson's correlation coefficient analysis. $\mathrm{P}<0.05$ was considered to indicate statistical significance.

\section{Results}

Patient characteristics. A total of 85 healthy and nulliparous women (age range, 18-29 years; mean age, 24.1 \pm 3.4 years) from five ethnic groups participated in the present study ( $n=17 /$ group). All subjects had neither current complaints nor a previous history of pelvic floor weakness, pelvic floor surgery or any known predisposing factor for pelvic floor dysfunction apart from chronic constipation in $12(14.1 \%)$ women. A total of $48(56.5 \%)$ participants were single while the remaining were married and/or sexually active.
Group characteristics. Participants were comparable regarding the various socio-demographic and medical characteristics (Tables I and II). Compared with the other groups, more Indian/Pakistani subjects were housewives and without university education. The overall prevalence of smoking and diseases suggestive of connective tissue weakness was low in all groups although both factors were more frequent in Italians. Associated gynaecological symptoms, particularly sexual dysfunction and chronic constipation, were also more common in this group (Table II). Presence of pelvic floor dysfunction in a first degree relative was reported by $7(8.2 \%)$ women (3 Bahrainis, 2 Italians, 1 Arab and 1 Filipino). Italians were taller and had higher BMI than other groups, and the differences were significant $(\mathrm{P}<0.001$; data not shown).

Plasma MMP and TIMP levels. ELISA assays of all plasma samples were considered technically adequate following duplicate analyses. Plasma levels for all markers were reported in $\mathrm{ng} / \mathrm{ml}$ except for TIMP-2 (pg/ml) because of lower assay sensitivity. There were statistically significant differences in all circulating marker measurements between Caucasians (Italians) and non-Caucasians (other groups) as depicted in Table III. Caucasians exhibited the highest levels of plasma MMP-9 and TIMP-1 compared with all other groups. Compared with in the Caucasians, the levels of plasma MMP-9 were significantly lower in the Indians/Pakistanis $(\mathrm{P}=0.015)$ and Bahrainis $(\mathrm{P}=0.009)$ but not in the other groups. MMP-2 plasma levels were similarly lower in all groups compared 
Table II. Medical characteristics of participants.

\begin{tabular}{|c|c|c|c|c|c|c|}
\hline Factor & Status & $\begin{array}{l}\text { Bahraini } \\
\mathrm{n}(\%)\end{array}$ & $\begin{array}{l}\text { Arab } \\
\mathrm{n}(\%)\end{array}$ & $\begin{array}{l}\text { Filipino } \\
\mathrm{n}(\%)\end{array}$ & $\begin{array}{l}\text { Indian/Pakistanis } \\
\mathrm{n}(\%)\end{array}$ & $\begin{array}{l}\text { Italian } \\
\mathrm{n}(\%)\end{array}$ \\
\hline \multicolumn{7}{|l|}{ Gynaecological symptoms } \\
\hline \multirow{2}{*}{$\begin{array}{l}\text { Menstrual cycles over } \\
\text { the last } 3 \text { months }\end{array}$} & Regular & $13(76.5)$ & $16(94.1)$ & $14(82.4)$ & $10(58.8)$ & $15(88.2)$ \\
\hline & Irregular & $4(23.5)$ & $1(5.9)$ & $3(17.6)$ & $7(41.2)$ & $2(11.8)$ \\
\hline \multirow[t]{2}{*}{ Infertility } & No & $17(100.0)$ & $17(100.0)$ & $17(100.0)$ & $15(88.2)$ & $17(100.0)$ \\
\hline & Yes & 0 & 0 & 0 & $2(11.8)$ & 0 \\
\hline \multirow[t]{2}{*}{ Abnormal uterine bleeding } & No & $17(100.0)$ & $17(100.0)$ & $17(100.0)$ & $15(88.2)$ & $14(82.4)$ \\
\hline & Yes & 0 & 0 & 0 & $2(11.8)$ & $3(17.6)$ \\
\hline \multirow[t]{2}{*}{ Hirsutism, acne } & No & $16(94.1)$ & $14(82.4)$ & $17(100.0)$ & $15(88.2)$ & $15(88.2)$ \\
\hline & Yes & $1(5.9)$ & $3(17.6)$ & 0 & $2(11.8)$ & $2(11.8)$ \\
\hline \multirow[t]{2}{*}{ Severe premenstrual symptoms } & No & $15(88.2)$ & $15(88.2)$ & $14(82.4)$ & $16(94.1)$ & $14(82.4)$ \\
\hline & Yes & $2(11.8)$ & $2(11.8)$ & $3(17.6)$ & $1(5.9)$ & $3(17.6)$ \\
\hline \multirow[t]{2}{*}{ Vaginitis } & No & $17(100.0)$ & $17(100.0)$ & $17(100.0)$ & $17(100.0)$ & $15(88.2)$ \\
\hline & Yes & 0 & 0 & 0 & 0 & $2(11.8)$ \\
\hline \multirow[t]{2}{*}{ Sexual dysfunction } & No & $17(100.0)$ & $17(100.0)$ & $17(100.0)$ & $17(100.0)$ & $14(82.4)$ \\
\hline & Yes & 0 & 0 & 0 & 0 & $3(17.6)$ \\
\hline \multicolumn{7}{|l|}{ Connective tissue disorders } \\
\hline \multirow[t]{2}{*}{ Hernia } & No & $17(100.0)$ & $17(100.0)$ & $17(100.0)$ & $17(100.0)$ & $16(94.1)$ \\
\hline & Yes & 0 & 0 & 0 & 0 & $1(5.9)$ \\
\hline \multirow[t]{2}{*}{ Varicose veins } & No & $17(100.0)$ & $16(94.1)$ & $16(94.1)$ & $17(100.0)$ & $13(76.5)$ \\
\hline & Yes & 0 & $1(5.9)$ & $1(5.9)$ & 0 & $4(23.5)$ \\
\hline \multirow[t]{2}{*}{ Excessive joint mobility } & No & $17(100.0)$ & $17(100.0)$ & $17(100.0)$ & $17(100.0)$ & $17(100.0)$ \\
\hline & Yes & 0 & 0 & 0 & 0 & 0 \\
\hline \multirow[t]{2}{*}{ Piles } & No & $17(100.0)$ & $15(88.2)$ & $16(94.1)$ & $17(100.0)$ & $17(100.0)$ \\
\hline & Yes & 0 & $2(11.8)$ & $1(5.9)$ & 0 & 0 \\
\hline \multirow{2}{*}{$\begin{array}{l}\text { Constipation ( }<3 \text { bowel movements/ } \\
\text { week for at least } 3 \text { months })\end{array}$} & No & $15(88.2)$ & $14(82.4)$ & $16(94.1)$ & $16(94.1)$ & $12(70.6)$ \\
\hline & Yes & $2(11.8)$ & $3(17.6)$ & $1(5.9)$ & $1(5.9)$ & $5(29.4)$ \\
\hline \multicolumn{7}{|l|}{ Medical history } \\
\hline \multirow{2}{*}{$\begin{array}{l}\text { Medical diseases or previous } \\
\text { surgical operations }\end{array}$} & No & $15(88.2)$ & $16(94.1)$ & $17(100.0)$ & $17(100.0)$ & $11(64.7)$ \\
\hline & Yes & $2(11.8)$ & $1(5.9)$ & 0 & 0 & $6(35.3)$ \\
\hline \multirow[t]{2}{*}{ Medication use } & No & $15(88.2)$ & $15(88.2)$ & $16(94.1)$ & $17(100.0)$ & $11(64.7)$ \\
\hline & Yes & $2(11.8)$ & $2(11.8)$ & $1(5.9)$ & 0 & $6(35.3)$ \\
\hline \multirow{2}{*}{$\begin{array}{l}\text { Symptoms suggestive of pelvic } \\
\text { floor dysfunction in mother } \\
\text { and/or sisters }\end{array}$} & No & $14(82.4)$ & $16(94.1)$ & $16(94.1)$ & $17(100.0)$ & $15(88.2)$ \\
\hline & Yes & $3(17.6)$ & $1(5.9)$ & $1(5.9)$ & 0 & $2(11.8)$ \\
\hline
\end{tabular}

Medical characteristics were determined according to routine clinical practise.

with in the Caucasians except in the Indian/Pakistani group, where they were higher $(\mathrm{P}=0.013)$. The extent of decrease was significant in the Bahrainis and Filipinos $(\mathrm{P}<0.001)$ but not in the Arab group. TIMP-1 plasma levels were significantly higher in the Caucasians compared with in the other groups except in the Bahrainis, for whom the difference was not significant $(\mathrm{P}=0.352)$. The greatest difference was observed in the Filipinos $(\mathrm{P}<0.001)$. Meanwhile, plasma TIMP-2 levels were higher in the Caucasians compared with in the Bahrainis and other Arabs, albeit to a non-significant extent $(\mathrm{P}=0.113$ and $\mathrm{P}=0.767$, respectively). Plasma levels of TIMP-2 in the Caucasians were lower than in the Filipino and
Indian/Pakistani groups, but the difference was only significant in the latter group $(\mathrm{P}=0.003)$. The distribution of plasma levels of MMP-2 and -9 and TIMP-1 and -2 in all groups is further illustrated in Figs. 1 and 2.

Correlation analyses indicated a negative correlation between plasma levels of MMP-2 and TIMP-2, and a positive correlation between plasma levels of MMP-9 and TIMP-1 in all groups. However, the correlations were not significant $(\mathrm{r}=0.071$, $\mathrm{P}=0.533$ and $\mathrm{r}=0.197, \mathrm{P}=0.8$, respectively). Furthermore, in all ethnic groups, MMP-9 plasma levels were significantly and positively correlated with BMI $(r=0.26, P=0.02)$, and TIMP-2 plasma levels were significantly and positively correlated with 
Table III. Comparison of plasma MMP and TIMP levels according to ethnic origin.

\begin{tabular}{|c|c|c|c|c|c|}
\hline Plasma marker & Ethnic group & Mean & $\begin{array}{l}\text { Standard } \\
\text { deviation }\end{array}$ & $\begin{array}{l}\text { Mean difference vs. } \\
\text { Italian group }\end{array}$ & P-value \\
\hline \multirow[t]{5}{*}{ MMP-2 (ng/ml) } & Italian & 9.95 & 1.13 & - & - \\
\hline & Bahraini & 8.81 & 0.55 & 1.13 & $<0.001$ \\
\hline & Arab & 9.61 & 0.94 & 0.34 & 0.27 \\
\hline & Filipino & 8.86 & 0.38 & 1.09 & $<0.001$ \\
\hline & Indian/Pakistani & 11.14 & 1.38 & -1.20 & 0.013 \\
\hline \multirow[t]{5}{*}{ MMP-9 (ng/ml) } & Italian & 27.77 & 3.40 & - & - \\
\hline & Bahraini & 26.08 & 5.48 & 1.69 & 0.009 \\
\hline & Arab & 24.59 & 8.90 & 3.19 & 0.248 \\
\hline & Filipino & 27.42 & 3.87 & 0.36 & 0.158 \\
\hline & Indian/Pakistani & 20.57 & 12.02 & 7.20 & 0.015 \\
\hline \multirow[t]{5}{*}{ TIMP-1 (ng/ml) } & Italian & 30.64 & 6.23 & - & - \\
\hline & Bahraini & 28.05 & 10.23 & 2.58 & 0.352 \\
\hline & Arab & 21.32 & 9.13 & 9.32 & 0.004 \\
\hline & Filipino & 19.63 & 6.02 & 11.00 & $<0.001$ \\
\hline & Indian/Pakistani & 21.90 & 10.19 & 8.73 & 0.013 \\
\hline \multirow[t]{5}{*}{ TIMP-2 (pg/ml) } & Italian & 13.16 & 11.56 & - & - \\
\hline & Bahraini & 10.04 & 14.11 & 3.12 & 0.113 \\
\hline & Arab & 12.91 & 14.08 & 0.26 & 0.767 \\
\hline & Filipino & 22.11 & 20.29 & -8.94 & 0.186 \\
\hline & Indian/Pakistani & 31.16 & 15.97 & -18.80 & 0.003 \\
\hline
\end{tabular}

P-values are representative of comparison with the Italian group. MMP, matrix metalloproteinase; TIMP, tissue inhibitor of metalloproteinase.

age $(\mathrm{r}=0.23, \mathrm{P}=0.045)$. There were no significant differences in the circulating levels of these markers in women with $(n=12)$ and without $(n=73)$ chronic constipation (data not shown).

\section{Discussion}

To the best of our knowledge, the present study is the first to investigate circulating MMP and TIMP as surrogate biomarkers of pelvic floor connective tissue integrity in a multi-ethnic group of young, nulliparous healthy women, in order to elucidate ethnic differences in the risk of developing pelvic floor dysfunctions. The results generally indicated that Caucasian women represented by the Italian cohort had higher plasma MMP-9 and MMP-2 but lower TIMP-1 levels than non-Caucasian women. This suggests that the critical balance between collagen formation and breakdown in the connective tissue, including that of the pelvic floor, is shifted in the latter direction in Caucasian women with a consequent decrease in connective tissue integrity and supportive function. This factor may explain the vulnerability of Caucasian women to develop pelvic floor dysfunctions.

Significant differences were observed in all markers between the five ethnic groups unlike a previous cardiology study of healthy male and female volunteers from four ethnic groups, where only MMP-9 levels were significantly different between groups (12). In addition, the results of this study revealed that plasma MMP-2 and -9 and TIMP-1 and -2 were not associated with anthropometric measurements including height or weight (12), and therefore this factor may not be responsible for the observed ethnic differences. The positive correlations between each of plasma MMP-9 and TIMP-1 levels and MMP-2 and TIMP-2 levels observed in the cardiologic study were either not significant or negative, respectively, in the present study subjects. Furthermore, the significant correlation observed in the cardiology study between age and plasma MMP-9 levels or with plasma TIMP-1 and -2 levels was only observed for plasma TIMP-2 levels in the current study. The present Filipino group exhibited the lowest plasma MMP-2 levels as opposed to MMP-9 levels in the cardiologic study. Although these differences in marker levels may result from inherent variations in laboratory analysis, including in specimen type (plasma or serum), sample processing (EDTA, citrate or heparin), storage time (rapid or prolonged) and freezing technique, differences in study populations may also be responsible $(12,14,17)$. Subjects were older and included both genders and an additional Afro-Caribbean ethnic subgroup in the cardiology study as opposed to women only and a different Middle-Eastern subgroup in the present cohort. Significant differences in circulating MMP-9 levels have been previously reported between smokers and non-smokers (18), confirming an impact of smoking that was not confirmed in the present study. Finally, there is some overlap between normal and abnormal circulating measurements of MMP and TIMP in healthy volunteers $(12,17)$. However, the measurement of plasma levels of MMP and TIMP performed in the current study appears more reliable than measurement techniques of serum levels in 

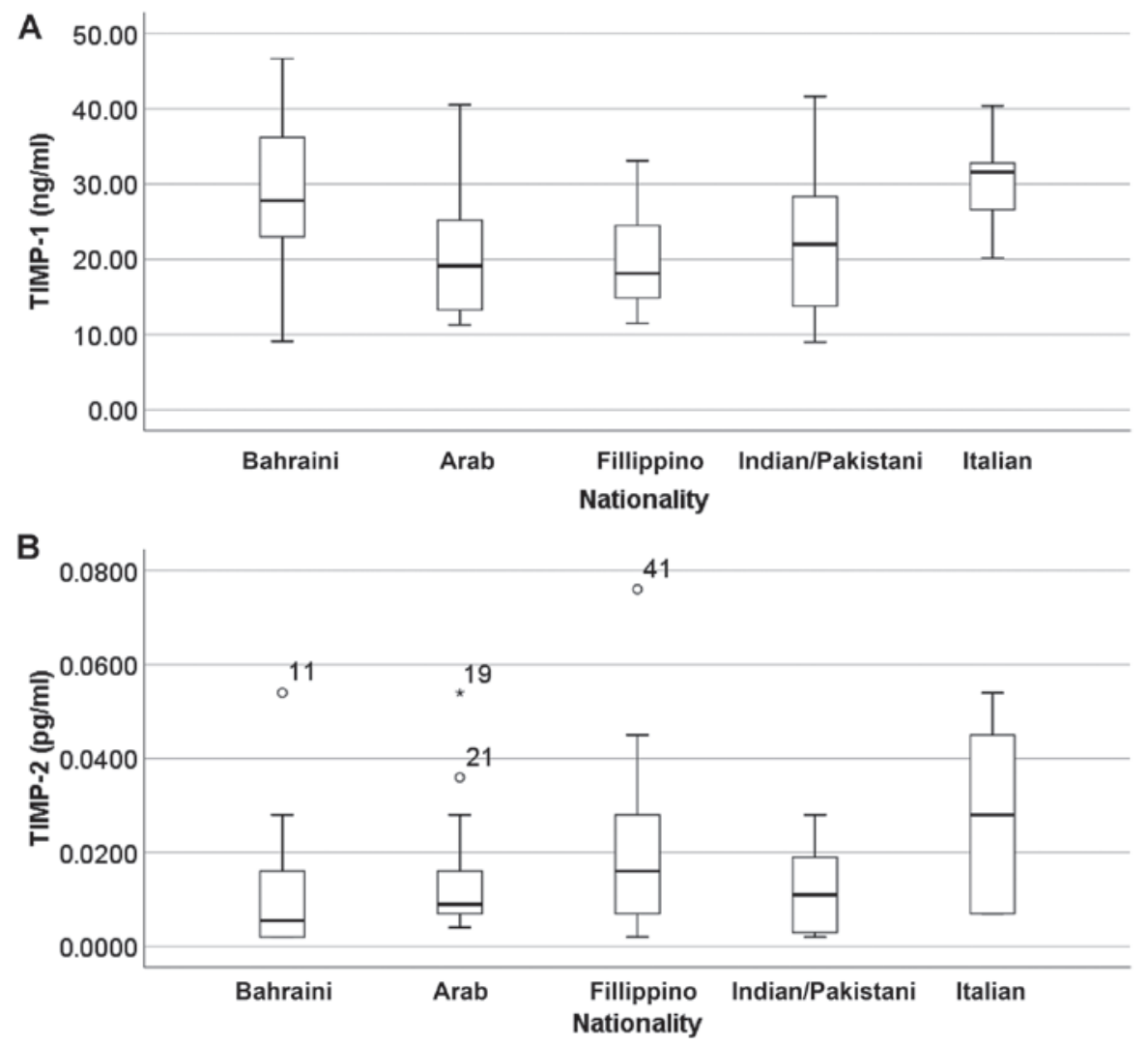

Figure 1. Box chart of the distribution of plasma levels of (A) TIMP-1 (ng/ml) and (B) TIMP-2 (pg/ml) in the five study groups. Hollow circles indicate outlier values and asterisk (") indicate extreme values, for which patient case numbers are shown. TIMP, tissue inhibitor of metalloproteinase.
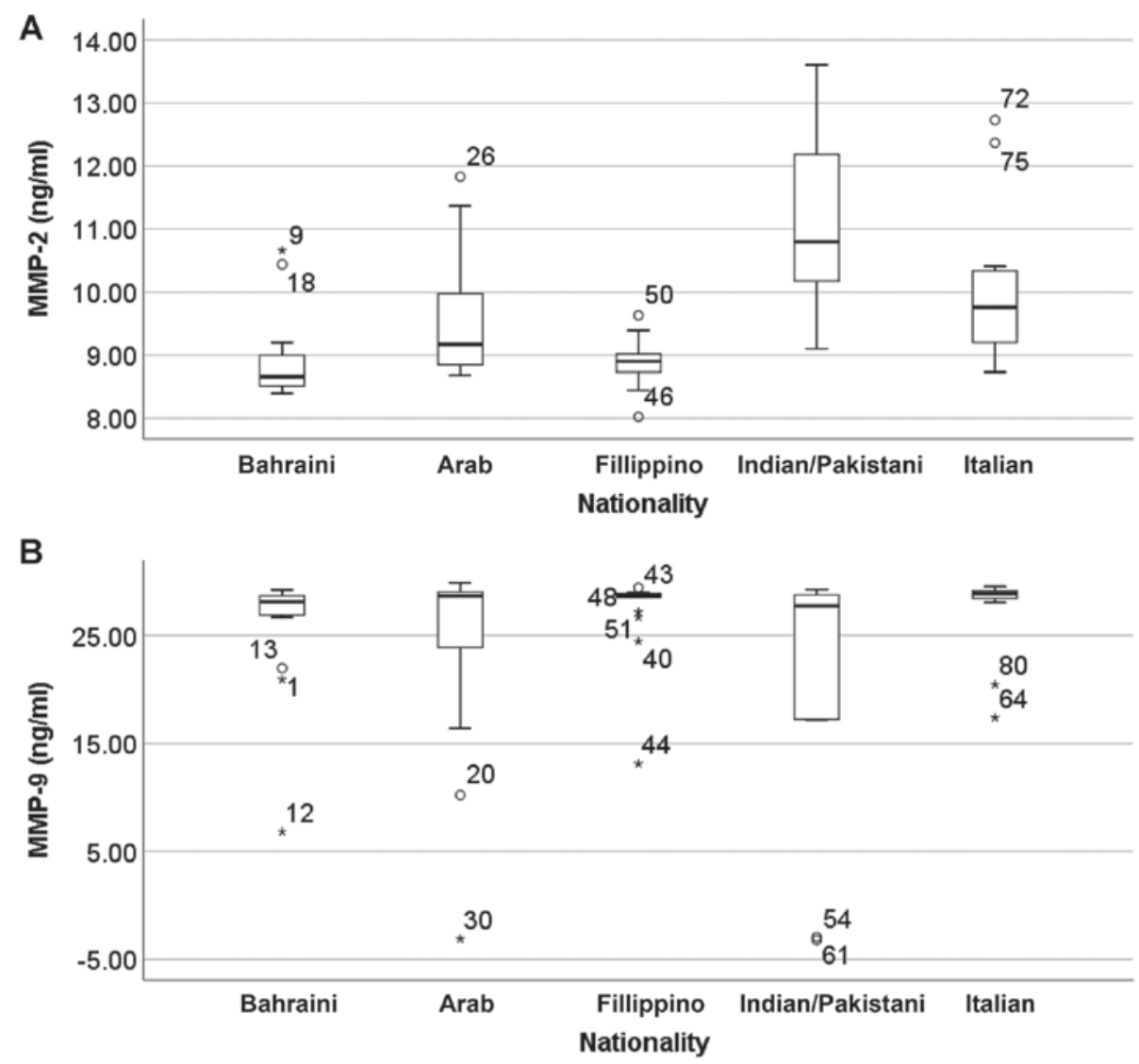

Figure 2. Box chart of the distribution of plasma levels of (A) MMP-2 (ng/ml) (B) MMP-9 (ng/ml) in the five study groups. Hollow circles indicate outlier values and asterisk (") indicate extreme values, for which patient case numbers are shown. MMP, matrix metalloproteinase. 
previous reports $(14,19)$, as it was less likely to be affected by measurement and storage conditions. In fact, plasma levels of MMP and TIMP in the current female population were within the range of previously observed plasma levels $(10-80 \mathrm{ng} / \mathrm{ml})$ in healthy volunteers from similar ethnic groups (12). Pelvic floor dysfunctions reportedly occur with a higher prevalence in Caucasian than in non-Caucasian women (8-10). This may result from differences in the frequency of reporting of symptoms as well as diagnosis, parity, BMI, lifestyle including diet, occupation, smoking and athletic exercise, position at delivery, micturition or defecation, socio-economic status and life expectancy (10). It may also be due to considerable genetic and ethnic variation in collagen metabolism of the pelvic floor connective tissue determined by the balance between MMP and TIMP activity (1-7). A relative increase in MMP/TIMP ratio may increase collagen turnover and decrease integrity, which could be responsible for the observed Caucasian vulnerability to support-related female pelvic floor dysfunctions. Although this assumption is theoretically plausible, clinical measurements of MMP and TIMP in women with pelvic floor dysfunctions has produced conflicting results. When evaluated independent of smoking status, serum MMP-9 levels in women with POP were similar to those of women without POP, suggesting that it was a poor measure for understanding the pathophysiology of the disorder (18). Furthermore, there was no significant difference between plasma levels of markers of collagen synthesis such as pro-collagen type 1-N pro-peptide, MMP-9 and vitamin C in patients with POP and/or SUI and controls. In another study, urinary collagenase assay of factors including MMP-1, -2 and -9 was the optimum pre-operative predictor of mid-urethral sling outcome in women with SUI, and revealed negative correlation with urethral closure pressure $(20,21)$.

Recent genotypic studies have identified molecular markers of dysfunction of the supportive pelvic floor connective tissue, with genetic polymorphism of MMP-1 and -9 identified in women with POP compared with controls $(22,23)$. Studying the genetic markers of ethnic risk for pelvic floor dysfunctions including MMP polymorphism in a population of healthy and nulliparous multi-ethnic women could similarly contribute to early detection and prevention of these disorders $(22,23)$. Identification of at-risk women with increased plasma MMP/TIMP ratio may be supported by further genetic evidence of polymorphism, using a simple blood test at a young age prior to first pregnancy. Referral of this subgroup for supervised interventions such as pelvic floor muscle training may minimize the consequences of pelvic floor trauma at childbirth. This work is now in progress by our group.

Limitations of the current study include selection bias since subject recruitment was not consecutive. In addition, determination of ethnicity is ambiguous since it is not dichotomous, has no scientific definition, is not synonymous with nationality and may be a cultural identification rather than a genetic indicator of biological difference (10). Furthermore, the study did not control for smoking, alcohol use, menstrual cycle phase or diet, each of which could affect circulating MMP and TIMP levels. It is also possible that plasma levels of MMP and TIMP are distinct and may not necessarily correlate with those in the pelvic floor soft tissues which was not assessed presently; such is a common problem for many tissue-based enzyme activities routinely detected in plasma $(4,5,18)$. Determining an association with pelvic floor connective tissue concentrations would require a biopsy, which on ethical grounds is not permissible in healthy volunteers.

Research on collagen metabolism in the pelvic floor in healthy women has been hampered by the limited availability of tissues for analysis, due to the difficulty of sampling and possibility of removing supportive tissues that could precipitate pelvic floor dysfunctions. Measurement of collagen biomarkers in the blood and/or urine is therefore a logical alternative. This preliminary study indicated differences in plasma levels of MMP-1 and - 9 and TIMP-1 and -2 between Caucasian and non-Caucasian young and nulliparous, healthy women with an apparently elevated MMP-9/TIMP-1 ratio in the former group. This suggests that collagen turnover in the connective tissue is higher in Caucasians with subsequent decrease in integrity and supportive function that could include the pelvic floor fascia. In this respect, plasma levels of MMP-1 and -9 and TIMP-2 may serve as potential biomarkers for predicting the development of pelvic floor dysfunctions in Caucasian women. Further studies in larger samples are now required to confirm these results. Additionally, studies of other existing markers for ethnic pelvic floor tissue integrity and their correlations with MMP-2 and -9 and TIMP-2 are required.

\section{Acknowledgements}

The authors are thankful to Mrs. Elanora Lachini, IRCCS San Raffaele Hospital, Milan, Italy, for her technical support with sample processing and transport, and to Dr A.K. Sandhu, Salmaniya Hospital, Manama, Bahrain, for aiding with volunteer recruitment in Bahrain.

\section{Funding}

The present study was supported by a research grant from the College of Medicine and Medical Sciences, Arabian Gulf University, Kingdom of Bahrain (grant no. 24-PI-01/15).

\section{Availability of data and materials}

The analysed datasets generated during the study are available from the corresponding author on reasonable request.

\section{Authors' contributions}

DR contributed to project development, and aided with management and analysis of the data, and manuscript writing and editing. KAK contributed to project development, and aided with data collection and management, and manuscript writing. AJ contributed to data management and analysis, and manuscript writing. DAT contributed to data collection, management and data analysis. MB contributed to project development and data collection. SS contributed to project development, data collection and manuscript editing.

\section{Ethics approval and consent to participate}

Ethical approval to conduct the present study was obtained from the Medical Research and Ethics Committee of the 
College of Medicine and Medical Sciences, Arabian Gulf University (Manama, Bahrain) and the San Raffaele Hospital (Milan, Italy). All participants provided informed consent for the use of their blood samples and data.

\section{Patient consent for publication}

All subjects gave informed consent for the publication of relevant data in the present study.

\section{Competing interests}

The authors declare that they have no competing interests.

\section{References}

1. Strinic T, Vulic M, Tomic S, Capkun V, Stipic I and Alujevic I: Matrix metalloproteinases-1, -2 expression in uterosacral ligaments from women with pelvic organ prolapse. Maturitas 64: 132-135, 2009.

2. Kerkhof MH, Hendriks L and Brölmann HA: Changes in connective tissue in patients with pelvic organ prolapse - a review of the current literature. Int Urogynecol J Pelvic Floor Dysfunct 20 461-474, 2009.

3. Gabriel B, Watermann D, Hancke K, Gitsch G, Werner M, Tempfer $\mathrm{C}$ and zur Hausen A: Increased expression of matrix metalloproteinase 2 in uterosacral ligaments is associated with pelvic organ prolapse. Int Urogynecol J Pelvic Floor Dysfunct 17: 478-482, 2006

4. Chen B, Wen Y, Wang H and Polan ML: Differences in estrogen modulation of tissue inhibitor of matrix metalloproteinase-1 and matrix metalloproteinase-1 expression in cultured fibroblasts from continent and incontinent women. Am J Obstet Gynecol 189: $59-65,2003$.

5. Min J, Li B, Liu C, Guo W, Hong S, Tang J and Hong L: Extracellular matrix metabolism disorder induced by mechanical strain on human parametrial ligament fibroblasts. Mol Med Rep 15: 3278-3284, 2017.

6. Suzme R, Yalcin O, Gurdol F, Gungor F and Bilir A: Connective tissue alterations in women with pelvic organ prolapse and urinary incontinence. Acta Obstet Gynecol Scand 86: 882-888, 2007.

7. Rahn DD, Acevedo JF and Word RA: Effect of vaginal distention on elastic fiber synthesis and matrix degradation in the vaginal wall: Potential role in the pathogenesis of pelvic organ prolapse. Am J Physiol Regul Integr Comp Physiol 295: R1351-R1358, 2008.

8. Howard D, Delancey JO, Tunn R and Ashton-Miller JA: Racial differences in the structure and function of the stress urinary continence mechanism. Obstet Gynecol 95: 713-717, 2000.

9. Sewell CA, Chang E and Sultana CJ: Prevalence of genital prolapse in 3 ethnic groups. J Reprod Med 52: 769-773, 2007.

10. Rizk DE, Czechowski J and Ekelund L: Dynamic assessment of pelvic floor and bony pelvis morphologic condition with the use of magnetic resonance imaging in a multiethnic, nulliparous, and healthy female population. Am J Obstet Gynecol 191: 83-89, 2004.
11. Easley DC, Abramowitch SD and Moalli PA: Female pelvic floor biomechanics: Bridging the gap. Curr Opin Urol 27: 262-267, 2017.

12. Tayebjee MH, Lip GY, Blann AD and Macfadyen RJ: Effects of age, gender, ethnicity, diurnal variation and exercise on circulating levels of matrix metalloproteinases (MMP)-2 and -9, and their inhibitors, tissue inhibitors of matrix metalloproteinases (TIMP)-1 and -2. Thromb Res 115: 205-210, 2005.

13. Barber MD, Walters MD and Bump RC: Short forms of two condition-specific quality-of-life questionnaires for women with pelvic floor disorders (PFDI-20 and PFIQ-7). Am J Obstet Gynecol 193: 103-113, 2005.

14. Peeters SA, Engelen L, Buijs J, Jorsal A, Parving HH, Tarnow L, Rossing P, Schalkwijk CG and Stehouwer CD: Plasma matrix metalloproteinases are associated with incident cardiovascular disease and all-cause mortality in patients with type 1 diabetes: A 12-year follow-up study. Cardiovasc Diabetol 16: 55, 2017.

15. Masuhara K, Nakai T, Yamaguchi K, Yamasaki S and Sasaguri Y: Significant increases in serum and plasma concentrations of matrix metalloproteinases 3 and 9 in patients with rapidly destructive osteoarthritis of the hip. Arthritis Rheum 46: 2625-2631, 2002.

16. Rouy D, Ernens I, Jeanty C and Wagner DR: Plasma storage at -80 degrees $C$ does not protect matrix metalloproteinase-9 from degradation. Anal Biochem 338: 294-298, 2005.

17. Tayebjee MH, Karalis I, Nadar SK, Beevers DG, MacFadyen RJ and Lip GY: Circulating matrix metalloproteinase-9 and tissue inhibitors of metalloproteinases- 1 and -2 levels in gestational hypertension. Am J Hypertens 18: 325-329, 2005.

18. Estanol MV, Crisp CC, Oakley SH, Kleeman SD, Fellner AN and Pauls RN: Systemic markers of collagen metabolism and vitamin $\mathrm{C}$ in smokers and non-smokers with pelvic organ prolapse. Eur J Obstet Gynecol Reprod Biol 184: 58-64, 2015.

19. Jung K: Serum or plasma: What kind of blood sample should be used to measure circulating matrix metalloproteinases and their inhibitors? J Neuroimmunol 162: 1-2, 2005.

20. Chai TC, Moalli PA, Richter HE, Lake AG, Kim HY, Nager CW, Sirls LT, Brubaker L and Kusek JW: Preoperative urodynamic parameters (Valsalva leak point pressure and maximum urethral closure pressure), urinary collagen and plasma vitamin D levels as predictors of mid urethral sling surgery outcome. J Urol 196: 819-823, 2016.

21. Chai TC, Richter HE, Moalli P, Keay S, Biggio J, Zong W, Curto T, Kim HY, Stoddard AM and Kusek JW: Inflammatory and tissue remodeling urinary biomarkers before and after mid urethral sling surgery for stress urinary incontinence. J Urol 191: 703-709, 2014.

22. Wu JM, Visco AG, Grass EA, Craig DM, Fulton RG, Haynes C, Weidner AC and Shah SH: Matrix metalloproteinase-9 genetic polymorphisms and the risk for advanced pelvic organ prolapse. Obstet Gynecol 120: 587-593, 2012.

23. Ferrari MM, Rossi G, Biondi ML, Viganò P, Dell'utri C and Meschia M: Type I collagen and matrix metalloproteinase 1, 3 and 9 gene polymorphisms in the predisposition to pelvic organ prolapse. Arch Gynecol Obstet 285: 1581-1586, 2012. 